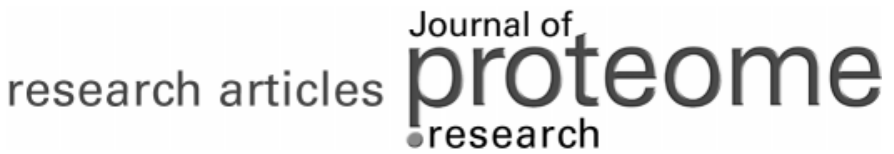

\section{Proteome Changes after Metabolic Engineering to Enhance Aerobic Mineralization of cis-1,2-Dichloroethylene}

\author{
Jintae Lee, ${ }^{\dagger}$ Li Cao, ${ }^{\dagger}$ Saw Yen Ow, ${ }^{\ddagger}$ Martin E. Barrios-Llerena, ${ }^{\ddagger}$ Wilfred Chen, ${ }^{\S}$ \\ Thomas K. Wood, ${ }^{\dagger}$ and Phillip C. Wright*,
}

\begin{abstract}
Artie McFerrin Department of Chemical Engineering and Department of Biology, 220 Jack E. Brown Building, Texas A \& M University, College Station, Texas 77843-3122, Biological \& Environmental Systems Group, Department of Chemical and Process Engineering, The University of Sheffield, Sheffield, S1 3JD United Kingdom, and Department of Chemical and Environmental Engineering, University of California, Riverside, California 92521

Received January 10, 2006
\end{abstract}

Metabolically engineered Escherichia coli has previously been used to degrade cis-1,2-dichloroethylene (cis-DCE). The strains express the six genes of an evolved toluene ortho-monooxygenase from Burkholderia cepacia G4 (TOM-Green, which formed a reactive epoxide) with either (1) $\gamma$-glutamylcysteine synthetase (GSHI*, which forms glutathione) and the glutathione $S$-transferase IsolLR1 from Rhodococcus AD45 (which adds glutathione to the reactive cis-DCE epoxide) or (2) with an evolved epoxide hydrolase from Agrobacterium radiobacter AD1 (EchA F108L/I219L/C248I which converts the reactive cis-DCE epoxide to a diol). Here, the impact of this metabolic engineering for bioremediation was assessed by investigating the changes in the proteome through a quantitative shotgun proteomics technique (iTRAO) by tracking the changes due to the sequential addition of TOM-Green, IsoILR1, and $\mathrm{GSHI}^{*}$ and due to adding the evolved EchA versus the wild-type enzyme to TOM-Green. For the TOMGreen/EchA system, 8 proteins out of 268 identified proteins were differentially expressed in the strain expressing EchA F108L/219L/C248I relative to wild-type EchA (e.g., EchA, protein chain elongation factor EF-Ts, 50S ribosomal subunits L7/L12/L32/L29, cysteine synthase A, glycerophosphodiester phosphodiesterase, iron superoxide dismutase). For the TOM-Green/IsolLR1/GSHI* system, the expression level of 49 proteins was changed out of 364 identified proteins. The induced proteins due to the addition of TOM-Green, IsolLR1, and GSHI* were involved in the oxidative defense mechanism, pyruvate metabolism, and glutathione synthesis (e.g., 30S ribosomal subunit proteins $\mathrm{S} 3$ and S16, 50S ribosomal subunit protein L20, alkyl hydroperoxide reductase, lactate dehydrogenase, acetate kinase, cysteine synthase A). Enzymes involved in indole synthesis, fatty acid synthesis, gluconeogenesis, and the tricarboxylic acid cycle were repressed (e.g., tryptophanase, acetyl-CoA carboxylase, phosphoenolpyruvate carboxykinase, malate dehydrogenase). Hence, the metabolic engineering that leads to enhanced aerobic degradation of $1 \mathrm{mM}$ cis-DCE (2.4-4-fold more chloride ions released) and reduced toxicity from cis-DCE epoxide results in enhanced synthesis of glutathione coupled with an induced stress response as well as repression of fatty acid synthesis, gluconeogenesis, and the tricarboxylic acid cycle.

Keywords: iTRAQ - metabolic engineering - toluene ortho-monooxygenase $\bullet \gamma$-glutamylcysteine synthetase $\bullet$ glutathione $S$-transferase $\bullet$ cis-1,2-dichloroethylene • quantitative proteomics

\section{Introduction}

cis-1,2-Dichloroethylene (cis-DCE) is a U.S. EPA priority pollutant, ${ }^{1}$ and degrading cis-DCE aerobically is important, since anaerobic degradation leads to formation of more toxic vinyl chloride, a human carcinogen. ${ }^{2}$ Previously, metabolic engineering was performed in our lab with Escherichia coli to detoxify cis-DCE using two different metabolic pathways. ${ }^{3,4}$ In both systems (Figure 1), toluene ortho-monooxygenase from Burkholderia cepacia G4 (TOM) was used to initiate attack of the chlorinated ethene. TOM consists of a $211-\mathrm{kDa}$ hydroxylase

* Corresponding author. Phone: +44 (0)114 222 7577. Fax: +44(0) 114 2227501. E-mail: p.c.wright@sheffield.ac.uk.

† Texas A \& M University.

$\ddagger$ The University of Sheffield.

${ }^{\S}$ University of California. encoded by tomA1A3A4 with two catalytic oxygen-bridged binuclear iron centers, a 40-kDa NADH-oxidoreductase encoded by tomA5, and a $10.4-\mathrm{kDa}$ electron-transfer protein encoded by tomA2. TOM-Green has a V106A mutation in the $\alpha$-subunit of the hydroxylase and has enhanced activity toward trichloroethylene, 1,1-dichloroethylene, and trans-dichloroethylene. ${ }^{5}$

The first detoxification strategy through cis-DCE epoxide was constructed by coexpressing TOM-Green with glutathione $S$-transferase (GST, specifically IsoILR1), and a variant of $\gamma$-glutamylcysteine synthetase (GSHI*), which allows overexpression of glutathione (GSH) by overcoming feedback inhibition (Figure 1). ${ }^{4}$ The engineered E. coli containing TOM-Green, IsoILR1, and GSHI* enhanced mineralization of cis-DCE 4-fold compared with the strain with only TOM-Green. ${ }^{4}$ 


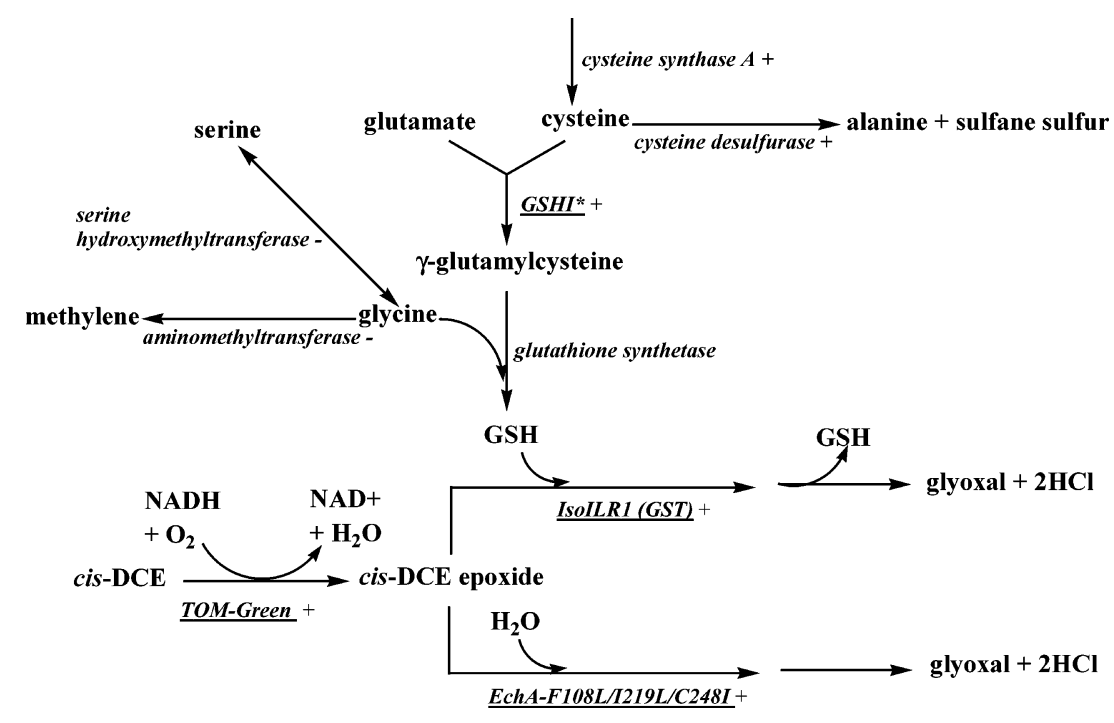

Figure 1. Detoxification pathway for cis-DCE by TG1/TOM-Green/IsolLR1/GSHI* and TG1/TOM-Green/EchA-F108L/I219L/C248I (cloned genes are underlined). The " + " indicates overexpression, while "-_ indicates repression of the proteins. Two arrows indicate multiple steps. Abbreviations: cis-DCE, cis-1,2-dichloroethylene; GSHI*, variant of $\gamma$-glutamylcysteine synthetase from E. coli; GSH, glutathione; GST, glutathione $S$-transferase; EchA, epoxide hydrolase from A. radiobacter AD1.

In the second detoxification strategy, GST and GSHI* were replaced by an epoxide hydrolase, which hydrolyzes reactive epoxides to the corresponding diol. Protein engineering through successive rounds of saturation mutagenesis was required to modify the epoxide hydrolase from Agrobacterium radiobacter AD1 (EchA, 294 aa) to accept cis-DCE epoxide as a substrate (Figure 1). ${ }^{3}$ When TOM-Green with the F108L/I219L/C248I variant of EchA was expressed, 10-fold more cis-DCE was mineralized than the strain containing TOM-Green with wildtype EchA. ${ }^{3}$

Recent advances in proteomics have allowed protein expression levels to be determined. A quantitative shotgun approach termed ITRAQ based on reporter ions using tandem mass spectrometry (MS/MS) has been developed. ${ }^{6}$ The approach uses a set of four isobaric reagents that label digested peptides from different samples, and the derivatized peptides in the mixture of samples can be identified and quantified using MS/ MS. Hence, this multiplex strategy simultaneously quantifies changes in protein expression level under four different biological conditions. ${ }^{6}$ The technique was successfully used in a proteomic expression analysis of the rhsA element, an unknown functional protein related to a transposon in E. coli. The study showed that 780 proteins in 17 functional categories could be identified. ${ }^{7}$ Here, we report the proteomic changes in E. coli engineered to express 7 to 9 genes for the degradation of cis-DCE. The metabolically engineered cells degrade more cis-DCE because of enhanced synthesis of glutathione. Although there are other interpretations possible and further work is required to study individual metabolic pathways, the enhanced degradation appears to be a result of induction of a stress response and up-regulation of some ribosomal subunit proteins, as well as repression of fatty acid synthesis, gluconeogenesis, and the tricarboxylic acid cycle.

\section{Materials and Methods}

Chemicals, Organisms, and Growth Conditions. All the chemicals were purchased from Fisher Scientific Company (Pittsburgh, PA) except cis-DCE (TCI America, Inc., Portland, OR). E. coli $\mathrm{TG}^{8}$ were routinely grown at $37{ }^{\circ} \mathrm{C}$ in chloride- free Luria-Bertani (LB) broth supplemented with $100 \mu \mathrm{g} / \mathrm{mL}$ kanamycin (Kan100), to maintain plasmids based on pBS(Kan), and $50 \mu \mathrm{g} / \mathrm{mL}$ chloramphenicol (Cam50) for maintaining plasmids pMMB206 or pMMB277. The strains were cultured with initial turbidity at $600 \mathrm{~nm}$ of $\sim 0.1$ from overnight cultures made from fresh single colonies. Isopropyl- $\beta$-D-thiogalactopyranoside (IPTG, $0.5 \mathrm{mM}$ ) was added to induce the expression of enzymes when the turbidity reached $0.3-0.35$. The exponentially grown cells were harvested after induction with IPTG for $2 \mathrm{~h}$, and washed three times with Tris- $\mathrm{HNO}_{3}$ buffer $(50 \mathrm{mM}$, $\mathrm{pH}$ 7.0) at room temperature to remove traces of chloride and metabolic byproducts. ${ }^{5}$

Enzyme Activity and Viability. cis-DCE degradation was measured through chloride ion release. The washed cells were adjusted to a turbidity of $2-3.5$ with Tris- $\mathrm{HNO}_{3}$ buffer, and 10 $\mathrm{mL}$ of these cells were contacted with $1 \mathrm{mM}$ cis-DCE together with $0.5 \mathrm{mM}$ IPTG and $5 \mathrm{mM}$ succinate in $60 \mathrm{~mL}$ vials at $37^{\circ} \mathrm{C}$ with shaking $(250 \mathrm{rpm})$. Samples $(1 \mathrm{~mL})$ were taken periodically for a chloride ion assay using the method of Canada et al. ${ }^{5}$ For the viability test, cells taken from the reaction were serially diluted using Tris- $\mathrm{HNO}_{3}$ buffer, placed on $\mathrm{LB}$ plates containing Kan100 and Cam50, and incubated at $37{ }^{\circ} \mathrm{C}$ overnight for colony counting.

Protein Extraction and Quantification. Data reproducibility in technical and biological replicates using the same protein extraction method described by Chong et al., ${ }^{9}$ and further analysis of that large dataset (C. S. Gan, University of Sheffield, unpublished analysis), reveals that the coefficient of variance (CV) is within a maximal range of 0.1 for iTRAQ labeling experiments in our hands. The information was used as a guideline for protein extraction in $E$. coli here.

After contact with the cis-DCE ( $1 \mathrm{mM}$ ) for $2 \mathrm{~h}$, E. coli cells (1 $\mathrm{mL}$ ) were transferred to microcentrifuge tubes, frozen with dry ice and $95 \%$ ethanol, and stored at $-80{ }^{\circ} \mathrm{C}$. Cells were thawed on ice and centrifuged at $13000 \mathrm{~g}$ for $15 \mathrm{~min}$, and the supernatants were discarded. The recovered pellets were resuspended in $500 \mu \mathrm{L}$ of TEAB buffer (90 mM triethylammonium bicarbonate, $\mathrm{pH}$ 8.6). Prior to cell disruption, the cell suspensions were allowed to incubate at room temperature for $15 \mathrm{~min}$. 
Crude protein extracts from each sample were obtained by lysing frozen $E$. coli in liquid nitrogen using a mortar and pestle. Liquid nitrogen was poured into the mortar before pipetting the suspended cells into the mortar. The cells were allowed to freeze and later ground into a fine powder using a cryogenically treated pestle. The grinding was repeated twice prior to recovering the powdered extracts into a clean microcentrifuge tube. The recovered extracts were sonicated for $10 \mathrm{~min}$ in an ice-cold water bath and subsequently centrifuged for $30 \mathrm{~min}$ at $21000 \mathrm{~g}$. The supernatant containing predominantly soluble proteins was transferred to a new microcentrifuge tube, while the insoluble pellets, which consisted of mostly insoluble proteins, were discarded. The soluble protein concentration was then determined using the RCDC assays (Bio-Rad).

Amine-Modifying Protein Labeling (iTRAQ Labeling). The quantified proteins $(100 \mu \mathrm{g})$ from each of the E. coli strains were transferred to a new microcentrifuge tube for iTRAQ labeling. The proteins were digested and labeled using the iTRAQ protocol and labeling kit (Applied Biosystems, CA) with some modification. Before running the protocol for the protein digest, a vial of trypsin was reconstituted in $25 \mu \mathrm{L}$ of $1 \mathrm{mM}$ hydrochloric acid. Aliquots $(3 \mu \mathrm{L})$ of reconstituted trypsin solution were added to each sample tube, and another $5 \mu \mathrm{L}$ of acetonitrile (ACN) was later added to the respective tubes. During the labeling process, $140 \mu \mathrm{L}$ of ethanol was added instead of 70 $\mu \mathrm{L}$. Samples were collected after labeling and stored at $-20^{\circ} \mathrm{C}$ prior to HPLC separation.

Cation Exchange Liquid Chromatography (LC). A liquid chromatographic peptide separation was achieved using a PolySULFOETHYL A Packed Column (PolyLC, Columbia, MD) with a $5 \mu \mathrm{m}$ particle size and a column dimension of $100 \mathrm{~mm}$ $\times 2.1$ mm i.d., $200 \AA$ pore size, on a BioLC HPLC unit (Dionex, Surrey, U.K.). The strong cation exchange (SCX) process utilized three separation buffers, A, B, and C. Buffer A had a graduated composition of $10 \mathrm{mM} \mathrm{KH}_{4} \mathrm{PO}_{4}$ and $25 \% \mathrm{ACN}$ at pH 2.97; buffer $\mathrm{B}$ was composed of $10 \mathrm{mM} \mathrm{KH} \mathrm{PO}_{4}, 25 \%$ ACN, and $500 \mathrm{mM}$ $\mathrm{KCl}$ at $\mathrm{pH}$ 2.97, while buffer $\mathrm{C}$ contained $10 \mathrm{mM} \mathrm{KH}_{4} \mathrm{PO}_{4}, 25 \%$ ACN, and $1 \mathrm{M} \mathrm{KCl}$ at $\mathrm{pH} 2.97$. The programmed gradients were $100 \%$ buffer A for 5 min, linear ramp from 0 to $21 \%$ buffer B for $2 \mathrm{~min}$, linear ramp from 21 to $31 \%$ buffer B for $3 \mathrm{~min}$, prolonged linear ramp from 31 to $50 \%$ B for $25 \mathrm{~min}, 50-100 \%$ buffer B for $10 \mathrm{~min}$, buffer B was dropped to $0 \%$, step increment of $42 \%$ buffer C, linear ramp $42-100 \%$ buffer C of $5 \mathrm{~min}$, hold $100 \%$ buffer $\mathrm{C}$ for 5 , and 5 min of $100 \%$ A. Total separation time was $60 \mathrm{~min}$. The injection volume was $200 \mu \mathrm{L}$, while the flow rate was maintained at $0.2 \mathrm{~mL} / \mathrm{min}$. The peptide separation was monitored through a UV Detector UVD170U by the Chromeleon software package version 6.50 (Dionex/LC Packings, The Netherlands). Peptide fractions were then collected at 1 min intervals using a Dionex Foxy Jr. Fraction Collector for $60 \mathrm{~min}$.

LC-MS/MS Analysis. Peptide separation was performed on an Ultimate chromatography system (Dionex-LC Packings, The Netherlands) interfaced to a QSTAR XL (Applied BiosystemsMDS Sciex) tandem mass spectrometer. Individual SCX fractions were injected and captured onto a $0.3 \times 5 \mathrm{~mm}$ trap column (3- $\mu \mathrm{m}$ C18 Dionex-LC Packings) and then eluted onto a $0.075 \times 150 \mathrm{~mm}$ analytical column (3- $\mu \mathrm{m}$ C18 Dionex-LC Packings) using an automated binary gradient $(300 \mathrm{~mL} / \mathrm{min})$ from $97 \%$ buffer A ( $3 \%$ ACN, $0.1 \%$ FA) to $45 \%$ buffer B $(97 \%$ ACN, $3 \%$ ACN, and $0.1 \% \mathrm{FA}$ ) over $75 \mathrm{~min}$, followed by $90 \% \mathrm{~B}$ for $5 \mathrm{~min}$. Survey scans were acquired from $\mathrm{m} / z$ 300-1800 with up to two precursors selected for MS/MS from $\mathrm{m} / z$ 65-2000 using dynamic exclusion. The collision energy range was $\sim 20 \%$ higher than that used for unlabeled peptides to overcome the stabilizing effect of the basic $\mathrm{N}$-terminal derivative and achieve equivalent fragmentation.

Data Analysis and Interpretation. Peptide and protein identifications were performed using Pro QUANT software v. 1.1 (Applied Biosystems, MDS Sciex) against a modified E. coli K-12 protein database (obtained from NCBI, April 2005) with the addition of the TOM-green protein sequences (4250 ORFs) and the EchA peptide (294 aa). The search used a mass tolerance of $0.45 \mathrm{Da}$ for the precursor mass and 0.3 $\mathrm{Da}$ for fragment masses, with MMTS as a cysteine fixed modification, and 1 missed cleavage was allowed. A list of protein identifications was generated using ProGroup Viewer v. 1.0.6 (Applied Biosystems, MDS Sciex), for single and multipeptide matches to a protein, with a probability cutoff of $95 \%$ to filter matches. ProGroup Viewer v. 1.0.6 is an updated version that fixed many of the software problems in v. 1.0.5. Only protein quantification data with relative expression of $>1.8$ and $<0.6$ was chosen to ensure up- and down-regulation authenticity. A guide to falsepositive identification was performed by matching the sample iTRAQ-labeled dataset from both systems against a nonrelated bacterium, Nostoc sp. PCC7120 (6055 ORFs, NCBI, August 2005), database using Pro QUANT software v. 1.1 (Applied Biosystems, MDS Sciex) at the $95 \%$ protein confidence interval. Corresponding peptide identifications above the $70 \%$ confidence interval in the Nostoc sp. 7120 list were cross-referenced (to remove common peptides) with the peptide identities obtained from the modified E. coli (4250 ORFs) database to quantitatively provide a guideline for false-positives identification. Single peptide hits for proteins were not generally used unless they had been manually checked by inspection (examination of coverage of $y, a, b$, and immonium ions) of spectra and de novo sequencing. Greater confidence for single peptides was given if they had been seen in separate MS experiments (as we performed multiple injections into the MS). The criteria, including the numbers of peptides and times seen, are given in the Supporting Information.

\section{Results}

Data Analysis, Proteome Coverage, de Novo Sequencing, and False-Positive Identification. There were 364 proteins identified above $95 \%$ protein confidence for the GSHI*/IsoILR1modified E. coli K12 (4250 ORFs) database using Pro QUANT software v. 1.1(Applied Biosystems, MDS Sciex) based on 4440 peptides. Similarly, a total of 268 positive protein hits were reported in the epoxide hydrolase (EchA) system, which were referenced to 3394 corresponding peptides. The expression ratio, $P$-value, and error factor for proteins identified from both systems were also calculated (Figure 4, and protein list; Supporting Information I and II) (Complete peptide list available upon request.)

There were 111 protein entries in the glutathione $S$-transferase system and 60 proteins in the epoxide hydrolase system that were identified by only one peptide (inclusive of replicates). These peptides identified were checked by ProQuant software v1.1 (Applied Biosystems, MDS Sciex) and were found to not have any immediate association with other proteins within the same proteome.

Only protein quantification data with relative expressions above +1.8 and below -0.6 were biologically considered to ensure the leverage of up- and down-regulation that was significant relative to the guideline $\mathrm{CV}$ of 0.1 discussed earlier. 
Table 1. Cell Viability after $1 \mathrm{mM}$ cis-DCE Mineralization by Whole E. coli Cells Expressing TOM-Green/EchA F108L/I219L/C248I or TOM-Green/IsoILR1/GSHI*

\begin{tabular}{|c|c|c|c|c|c|c|c|}
\hline & & \multicolumn{6}{|c|}{ Viable cells, cells/mL } \\
\hline & & $\begin{array}{l}\text { TOM-Green/ } \\
\text { EchA wild-type }^{a}\end{array}$ & $\begin{array}{l}\text { TOM-Green/EchA } \\
\text { F108L/I219L/C248I }{ }^{a}\end{array}$ & $\begin{array}{l}\text { pBS(Kan) })^{-/} \\
\text {pMMB2 }^{b}\end{array}$ & $\begin{array}{l}\text { TOM-Green/ } \\
\text { pMMB277 }\end{array}$ & $\begin{array}{l}\text { TOM-Green/ } \\
\text { IsoILR1 }^{b}\end{array}$ & $\begin{array}{l}\text { TOM-Green/ } \\
\text { IsoILR1/GSHI*b }\end{array}$ \\
\hline Time & $\begin{array}{l}0 \mathrm{~min} \\
120 \mathrm{~min}\end{array}$ & $\begin{array}{l}(1.7 \pm 0.2) \times 10^{8} \\
(0.57 \pm 0.06) \times 10^{8}\end{array}$ & $\begin{array}{l}(1.40 \pm 0.08) \times 10^{8} \\
(0.42 \pm 0.01) \times 10^{8}\end{array}$ & $\begin{array}{l}(1.49 \pm 0.08) \times 10^{8} \\
(1.1 \pm 0.1) \times 10^{8}\end{array}$ & $\begin{array}{l}(1.30 \pm 0.03) \times 10^{8} \\
(0.7 \pm 0.3) \times 10^{8}\end{array}$ & $\begin{array}{l}(1.46 \pm 0.17) \times 10^{8} \\
(0.72 \pm 0.11) \times 10^{8}\end{array}$ & $\begin{array}{l}(1.96 \pm 0.19) \times 10^{8} \\
(1.3 \pm 0.1) \times 10^{8}\end{array}$ \\
\hline Viability, \% & & $38 \pm 6$ & $30.5 \pm 0.7$ & $79 \pm 4$ & $62 \pm 6$ & $52 \pm 4$ & $73 \pm 8$ \\
\hline $\mathrm{Cl}^{-}$formation, $\mu \mathrm{M}$ & & 482 & 1017 & 0 & 64 & 179 & 235 \\
\hline $\begin{array}{l}\mathrm{Cl}^{-} \text {formation, } \\
(\mathrm{mmol} / \mathrm{min}) / \mathrm{mg} \text { protein }\end{array}$ & & 2.96 & 6.54 & 0 & 0.64 & 1.25 & 2.53 \\
\hline
\end{tabular}

${ }^{a}$ E. coli TG1/pMMB206-TOM-Green/pBS(Kan)-EchA and E. coli TG1/pMMB206-TOM-Green/pBS(Kan)-EchA F108L/I219L/C248I. ${ }^{b}$ E. coli TG1/pBS(Kan)-/ pMMB277, E. coli TG1/pBS(Kan)-TOM-Green/pMMB277, E. coli TG1/pBS(Kan)-TOM-Green/pMMB277-IsoILR1, and E. coli TG1/pBS(Kan)-TOM-Green/ pMMB277-IsoILR1-GSHI*.

Peptide dataset matching using ProGroup Viewer v. 1.0.6 (Applied Biosystems, MDS Sciex) for false-positive identification also revealed none of the 103 peptide sequences matched in Nostoc sp. 7120 were found in the 4440 peptides identified from the $E$. coli protein database for the glutathione $S$-transferase system. This was also true for the false-positive study conducted on the EchA system, as none of the 132 peptides matched in Nostoc sp. 7120 were matched with the 3394 peptides in the epoxide hydrolase system. The false-positive identification factor determined was therefore 0.0232 (2.32\%) for the glutathione $S$-transferase system and 0.0388 (3.88\%) for the epoxide hydrolase system (false-positive identification list; Supporting Information I and II) on this basis.

Four selected proteins identified by a single distinct peptide hit in the glutathione $S$-transferase system (Table 2, and low peptide MS check; Supporting Information) and two from the epoxide hydrolase system (Table 3, and low peptide MS check Supporting Information VI) were manually checked for any misinterpretation of the MS/MS experiments by ProQuant 1.1 (Applied Biosystems, MDS Sciex) on the coverage of $y, a, b$, and immonium ions during TOF. Manual checking confirmed satisfactory ion matching for all six identifications (accession numbers: glutathione-S-transferase system, 16128171, 16129055, 16130807, and 16131507; epoxide hydrolase system, 16131191 and 16129052). Although the coverage for theoretical y and $b$ series ions was not complete in two of the six proteins, the abundant presence of less specific fragment immonium ions was sufficient in identifying most if not all of the amino acid fingerprints in the corresponding peptide (ion chromatograms; Supporting Information VI), hence, sufficiently validating their identifications.

The proteome coverage obtained by the 364 proteins obtained using iTRAQ labeling contained more acidic proteins than of comparable basic variants. The total tally of acidic proteins found here accounts for over $75 \%$ of the spread across the E. coli proteome (Figure 2). Similarly, acidic proteins found in the epoxide hydrolase system also accounts for $75 \%$ of the spread across the model proteome.

Mineralization of cis-DCE and Cell Viability. We metabolically engineered two systems to degrade cis-DCE with both systems relying on initial attack from TOM-Green ${ }^{3}$ to form a reactive cis-DCE epoxide: in the first system, GST (IsoILR1) adds glutathione to the cis-DCE epoxide, and in the second system, an engineered epoxide hydrolase (EchA F108L/I219L/ C248I) adds water to the cis-DCE epoxide (Figure 1). Both adducts are unstable and degrade to release free chloride, so cis-DCE is mineralized. Here, $1 \mathrm{mM}$ cis-DCE was converted to chloride (Table 1), and these values agree with our previous reports. ${ }^{3,4}$
To measure cell viability, cells were withdrawn using the same reaction conditions. The number of viable cells decreased after $2 \mathrm{~h}$ of degradation of cis-DCE for all the strains (Table 1). The introduction of the GST and GSHI* increased cell viability, since the TOM-Green/IsoILR1/GSHI* system had the highest number of viable cells (73 $\pm 8 \%$ vs $62 \pm 6 \%$ for TOM-Green alone); this increase is more significant than the absolute viability numbers indicate, because the TOM-Green/IsoILR1/ GSHI* system generated 4-fold more chloride and toxic intermediates than the TOM-Green system (Table 1). Although there was no significant difference in the number of viable cells after contact with cis-DCE between the TOM-Green/wild-type EchA and TOM-Green/EchA F108L/I219L/C248I cultures (38 $\pm 6 \%$ vs $30.5 \pm 0.7 \%$ ) (Table 1 ), if one takes into account that 2.2 fold more chloride as well as 2.2-fold more toxic intermediates, cis-DCE epoxide, and glyoxal (Figure 1) were generated in the TOM-Green/EchA F108L/I219L/C248I culture, it is concluded that there was less toxicity with the engineered epoxide hydrolase system, too.

Glutathione $S$-Transferase System Proteome. Samples from all four strains were digested and labeled individually with iTRAQ reagents and analyzed simultaneously by LC-MS/MS. A total of 364 proteins was identified on the basis of singleand multipeptide matches to a protein, with a probability cutoff of $95 \%$. Concentrations of 49 out of the 364 proteins were changed significantly after contact with $1 \mathrm{mM}$ cis-DCE in the three strains with TOM-Green compared to the control strain without TOM-Green. Enzymes involved in the detoxification of cis-DCE, carbon flux, fatty acid synthesis, and oxidative stress were impacted.

As expected, of the three strains containing TOM-Green, the TOM-Green $\alpha$ subunit (519 aa, encoded by tomA3), $\beta$ subunit (331 aa, encoded by tomA1), and $\gamma$ subunit (118 aa, encoded by tomA4) of the hydroxylase were detected along with the NADH-oxidoreductase (354 aa, encoded by tomA5); the concentrations of these TOM proteins were 2-9-fold higher concentrations than the control which lacked TOM-Green (Table 2). Also, there was no significant difference in the expression of these subunits in the three strains which expressed TOM-Green, so the remaining effects were the result of metabolic engineering, not TOM-Green expression. Also, as expected, $\gamma$-glutamylcysteine synthetase (GSHI*) was identified and found to be present in an 8.6-fold greater concentrations in TG1/TOM-Green/IsoILR1/GSHI* than in the three strains that did not express this enzyme (Figure 1, Table 2).

One result of trying to increase glutathione production by introducing the $\gamma$-glutamylcysteine synthetase gene (GSHI*, combines glutamate and cysteine), was that the metabolically engineered cells responded by inducing the machinery required 
Table 2. Relative Protein Expression of E. coli TG1 Cells Expressing TOM-Green, TOM-Green/IsolLR1, or TOM-Green/IsolLR1/GSHI* Relative to Cells Which Lack These Enzymes

\begin{tabular}{|c|c|c|c|c|c|c|c|c|c|c|c|}
\hline \multirow[b]{2}{*}{ Protein Name } & \multicolumn{2}{|c|}{ Peptides $>70 \%$ Confidence } & \multirow[b]{2}{*}{ ID number } & \multirow[b]{2}{*}{ Gene } & \multirow[b]{2}{*}{ Synonym } & \multirow[b]{2}{*}{ Ratio $^{b}$} & \multirow[b]{2}{*}{ EF Ratio ${ }^{b}$} & \multirow[b]{2}{*}{ Ratio $^{c}$} & \multirow[b]{2}{*}{ EF Ratio ${ }^{c}$} & \multirow[b]{2}{*}{ Ratio $^{d}$} & \multirow[b]{2}{*}{ EF Ratio } \\
\hline & Total & Distinct & & & & & & & & & \\
\hline TOM $\alpha$ subunit & 105 & 13 & $\mathrm{~N}^{a}$ & tomA3 & $\mathrm{N}^{a}$ & 8.44 & 1.31 & 4.72 & 1.27 & 8.28 & 1.32 \\
\hline TOM $\beta$ subunit & 57 & 12 & $\mathrm{~N}^{a}$ & tomAl & $\mathrm{N}^{a}$ & 5.52 & 1.28 & 6.99 & 1.24 & 3.92 & 1.25 \\
\hline TOM $\gamma$ subunit & 17 & 3 & $\mathrm{~N}^{a}$ & tomA4 & $\mathrm{N}^{a}$ & 4.68 & 1.71 & 5.10 & 1.66 & 9.07 & 1.91 \\
\hline TOM reductase & 6 & 3 & $\mathrm{~N}^{a}$ & tomA5 & $\mathrm{N}^{a}$ & 3.30 & 2.46 & 2.35 & 2.37 & 2.64 & 2.29 \\
\hline$\gamma$-glutamate-cysteine synthetase & 26 & 7 & b2688 & $g \operatorname{sh} A$ & b2688 & 0.89 & 1.19 & 0.96 & 1.21 & 8.65 & 1.40 \\
\hline 30 S ribosomal subunit protein S13 & 40 & 5 & 16131177 & rpsM & b3298 & 2.19 & 1.15 & 0.85 & 1.06 & 1.99 & 1.21 \\
\hline 30S ribosomal subunit protein S16 & 6 & 3 & 16130530 & $r p s P$ & b2609 & 1.98 & 2.33 & 1.02 & 1.58 & 2.63 & 2.61 \\
\hline 30S ribosomal subunit protein S3 & 47 & 8 & 16131193 & rpsC & b3314 & 2.28 & 1.21 & 1.26 & 1.08 & 1.73 & 1.34 \\
\hline 50S ribosomal subunit protein L19 & 24 & 5 & 16130527 & $r p l s$ & b2606 & 2.79 & 1.19 & 1.30 & 1.16 & 2.54 & 1.35 \\
\hline $\begin{array}{l}\text { 50S ribosomal subunit protein L20, } \\
\text { also post-translational autoregulator }\end{array}$ & 6 & 2 & 16129672 & rplT & b1716 & 3.65 & 1.37 & 1.45 & 1.18 & 2.73 & 2.43 \\
\hline 50S ribosomal subunit protein L30 & 11 & 2 & 16131181 & $\operatorname{rpmD}$ & b3302 & 1.51 & 1.25 & 1.09 & 1.51 & 1.83 & 1.18 \\
\hline 50S ribosomal subunit protein L32 & 8 & 2 & 16129052 & rpmF & b1089 & 2.79 & 1.20 & 3.32 & 2.10 & 1.28 & 1.16 \\
\hline $50 \mathrm{~S}$ ribosomal subunit protein L33 & 7 & 1 & 16131507 & rрmG & b3636 & 1.55 & 1.14 & 1.65 & 1.27 & 2.58 & 1.46 \\
\hline $\begin{array}{l}\text { 50S ribosomal subunit protein L4, } \\
\text { regulates expression of S10 operon }\end{array}$ & 40 & 6 & 16131198 & $r p l D$ & b3319 & 2.10 & 1.43 & 1.30 & 1.47 & 1.39 & 1.39 \\
\hline $\begin{array}{l}\text { cysteine synthase A } \\
\text { Pont }\end{array}$ & 24 & 8 & 16130340 & cysK & b2414 & 0.32 & 1.18 & 0.37 & 1.16 & 2.21 & 1.35 \\
\hline sulfite reductase, $\alpha$ subunit & 2 & 2 & 16130670 & cysI & b2763 & 0.39 & 2.27 & 0.48 & 2.24 & 0.91 & 6.04 \\
\hline cysteine desulfurase & 17 & 6 & 49176235 & iscS & b2530 & 1.22 & 1.19 & 1.23 & 1.18 & 1.91 & 1.30 \\
\hline $\begin{array}{l}\text { aminomethyltransferase of glycine } \\
\text { cleavage system }^{e}\end{array}$ & 1 & 1 & 16130807 & gcvT & b2905 & 0.18 & * & 0.16 & * & 0.47 & * \\
\hline Tryptophanase & 120 & 18 & 49176396 & $\operatorname{tnaA}$ & b3708 & 0.19 & 1.11 & 0.15 & 1.12 & 0.13 & 1.15 \\
\hline $\begin{array}{l}\text { Succinate dehydrogenase, } \\
\mathrm{Fe}-\mathrm{S} \text { protein }\end{array}$ & 8 & 2 & 16128699 & $s d h B$ & b0724 & 0.67 & 1.22 & 0.77 & 1.31 & 0.51 & 1.35 \\
\hline malate dehydrogenase & 37 & 7 & 16131126 & $m d h$ & b3236 & 0.35 & 1.20 & 0.46 & 1.15 & 0.40 & 1.19 \\
\hline phosphoenolpyruvate carboxykinase & 11 & 6 & 16131280 & pckA & b3403 & 0.47 & 1.51 & 0.59 & 1.48 & 0.43 & 1.62 \\
\hline global regulator, starvation conditions & 15 & 3 & 16128780 & $d p s$ & b0812 & 1.45 & 1.19 & 1.84 & 1.29 & 1.85 & 1.21 \\
\hline acetate kinase & 5 & 3 & 16130231 & ackA & b2296 & 1.88 & 1.51 & 1.13 & 3.41 & 3.78 & 3.41 \\
\hline L-lactate dehydrogenase & 3 & 2 & 16131476 & lldD & b3605 & 1.47 & 1.54 & 1.55 & 1.22 & 1.63 & 1.47 \\
\hline $\begin{array}{l}\text { acetyl-CoA carboxylase (biotin } \\
\text { carboxylase subunit) }\end{array}$ & 3 & 2 & 16131144 & $\operatorname{accC}$ & b3256 & 0.69 & 1.61 & 0.94 & 1.44 & 0.38 & 2.55 \\
\hline $\begin{array}{l}\text { malonyl-CoA-[acyl-carrier-protein] } \\
\text { transacylase }^{e}\end{array}$ & 2 & 1 & 16129055 & $f a b D$ & b1092 & 0.46 & 7.73 & 0.60 & 1.72 & 0.75 & 3.95 \\
\hline $\begin{array}{l}\text { Glycine tRNA synthetase, } \\
\beta \text { subunit }\end{array}$ & 15 & 6 & 16131430 & glyS & b3559 & 1.32 & 1.31 & 1.28 & 1.17 & 1.73 & 1.63 \\
\hline $\begin{array}{l}\text { alkyl hydroperoxide reductase } \\
\text { subunit }\end{array}$ & 21 & 4 & 16128589 & $a h p F$ & b0606 & 4.06 & 1.43 & 3.07 & 1.13 & 1.90 & 1.22 \\
\hline $\begin{array}{l}\text { aminoacyl-histidine dipeptidase } \\
\text { (peptidase D) }\end{array}$ & 5 & 3 & 16128223 & pepD & b0237 & 0.37 & 1.67 & 0.71 & 1.26 & 0.81 & 1.22 \\
\hline $\begin{array}{l}\text { carbamoyl phosphate synthase, } \\
\text { large subunit }\end{array}$ & 3 & 3 & 16128027 & $\operatorname{carB}$ & b0033 & 1.41 & 2.88 & 1.02 & 2.21 & 1.26 & 2.64 \\
\hline catalase, hydroperoxidase HPI(I) & 11 & 4 & 16131780 & katG & b3942 & 1.79 & 1.50 & 1.24 & 1.54 & 1.82 & 1.44 \\
\hline $\begin{array}{l}\text { chaperone Hsp90, heat shock } \\
\text { protein C } 62.5\end{array}$ & 46 & 14 & 16128457 & htpG & b0473 & 1.34 & 1.15 & 1.71 & 1.11 & $\begin{array}{l}1.02 \\
1.82\end{array}$ & 1.34 \\
\hline $\begin{array}{l}\text { DNA-bending protein with } \\
\text { chaperone activity }\end{array}$ & 2 & 2 & 16130583 & $\operatorname{stpA}$ & b2669 & 1.00 & 1.94 & 1.25 & 2.30 & 1.70 & 1.89 \\
\hline $\begin{array}{l}\text { fructose-bisphosphate aldolase, } \\
\text { class II }\end{array}$ & 20 & 4 & 16130826 & fbaA & b2925 & 0.55 & 1.27 & 0.70 & 1.12 & 1.15 & 1.28 \\
\hline $\begin{array}{l}\text { glycerophosphodiester } \\
\text { phosphodiesterase, periplasmic }\end{array}$ & 10 & 6 & 16130174 & $g l p Q$ & b2239 & 0.46 & 1.75 & 0.55 & 1.31 & 0.49 & 1.83 \\
\hline inorganic pyrophosphatase & 8 & 3 & 16132048 & рра & b4226 & 1.04 & 1.42 & 1.44 & 1.16 & 0.41 & 2.87 \\
\hline $\begin{array}{l}\text { membrane-bound ATP synthase, } \\
\text { delta-subunit }\end{array}$ & 7 & 2 & 16131603 & atpH & b3735 & 0.49 & 1.35 & 0.49 & 1.29 & 0.66 & 1.22 \\
\hline NADH dehydrogenase I chain I & 9 & 3 & 16130216 & пиог & b2281 & 0.68 & 1.20 & 0.83 & 1.21 & 0.36 & 1.40 \\
\hline nucleoside diphosphate kinase & 7 & 2 & 16130443 & $n d k$ & b2518 & 0.52 & 1.30 & 0.60 & 1.27 & 0.36 & 1.48 \\
\hline $\begin{array}{l}\text { oligopeptide transport protein } \\
\text { (ABC superfamily) }\end{array}$ & 10 & 5 & 16129204 & оррА & b1243 & 0.41 & 1.16 & 0.79 & 1.25 & 0.64 & 1.55 \\
\hline $\begin{array}{l}\text { periplasmic glucans biosynthesis } \\
\text { protein }\end{array}$ & 4 & 3 & 16129011 & $m d o G$ & b1048 & 0.94 & 2.16 & 1.40 & 1.57 & 0.83 & 4.26 \\
\hline $\begin{array}{l}\text { periplasmic chaperone for outer } \\
\text { membrane proteins }{ }^{e}\end{array}$ & 5 & 1 & 16128171 & hlpA & b0178 & 2.45 & 1.38 & 1.09 & 1.43 & 6.69 & 1.38 \\
\hline serine hydroxymethyltransferase & 11 & 4 & 16130476 & glyA & b2551 & 0.28 & 1.42 & 0.45 & 1.34 & 0.45 & 2.00 \\
\hline $\begin{array}{l}\text { soluble pyridine nucleotide } \\
\text { transhydrogenase }\end{array}$ & 3 & 2 & 16131800 & udhA & b3962 & 0.72 & 1.54 & 0.97 & 1.51 & 0.65 & 2.03 \\
\hline Superoxide dismutase, iron & 3 & 2 & 16129614 & $\operatorname{sod} B$ & b1656 & 0.52 & 2.74 & 0.36 & 1.54 & 0.83 & 2.93 \\
\hline $\begin{array}{l}\text { threonine 3-dehydrogenase, } \\
\text { NAD(P)-binding }\end{array}$ & 7 & 3 & 16131487 & $t d h$ & b3616 & 0.67 & 1.39 & 0.47 & 1.55 & 0.99 & 1.46 \\
\hline triosephosphate isomerase & 3 & 2 & 16131757 & tpiA & b3919 & 0.58 & 2.64 & 0.67 & 1.78 & 0.91 & 3.08 \\
\hline $\begin{array}{l}\text { uridine phosphorylase } \\
\text { une }\end{array}$ & 9 & 3 & 16131680 & $u d p$ & b3831 & 1.54 & 1.33 & 1.40 & 1.21 & 2.14 & $\begin{array}{l}1.39\end{array}$ \\
\hline
\end{tabular}

${ }^{a} \mathrm{~N}$ : no corresponding number or synonym in E. coli $\mathrm{K} 12$ complete genome since proteins are cloned from B. cepacia G4. ${ }^{b}$ Ratio: ratio of expression level in strain TG1/pBS(Kan)-TOM-Green/pMMB277- vs TG1/pBS(Kan)-/pMMB277-. ${ }^{c}$ Ratio: ratio of expression level in strain TG1/pBS(Kan)-TOM-Green/pMMB277IsoILR1 vs TG1/pBS(Kan)-/pMMB277-. ${ }^{d}$ Ratio: ratio of expression level in strain TG1/pBS(Kan)-TOM-Green/pMMB277-IsoILR1-GSHI* vs TG1/pBS(Kan)-/ pMMB277-. ${ }^{e}$ De novo sequencing and manual checking done.

for the synthesis of cysteine and glycine (glutathione consists of cysteine, glutamate, and glycine) (Figure 1). Expression of $\gamma$-glutamylcysteine synthetase in TG1/TOM-Green/IsoILR1/ GSHI* caused a 5.9-7-fold-induction of cysteine synthase A ( $O$-acetylserine sulfhydrolase A, encoded by $c y s K$ ), the enzyme which synthesizes cysteine and acetate from $O$-acetyl-L-serine and $\mathrm{H}_{2} \mathrm{~S}$ (Figure 1 ),${ }^{10}$ compared to the strains with either TOMGreen or TOM-Green/IsoILR1. Increasing cysteine, the substrate of $\gamma$-glutamylcysteine synthetase, should allow for greater glutathione synthesis and greater cis-DCE degradation due to the active glutathione $S$-transferase (GST) (Figure 1). Note that 9-fold more intracellular glutathione was measured after adding 
Table 3. Relative Protein Expression of E. coli TG1 Cells Expressing TOM-Green/EchA F108L/I219L/C248I Relative to TOM-Green/ Wild-Type EchA

\begin{tabular}{|c|c|c|c|c|c|c|c|}
\hline Protein Name & ID number & Gene & Synonym & $\begin{array}{l}\text { Total } \\
>70 \%\end{array}$ & $\begin{array}{l}\text { Distinct } \\
>70 \%\end{array}$ & Ratio $^{a}$ & $\mathrm{EF}^{a}$ \\
\hline EchA & $\mathrm{N}^{b}$ & echA & $\mathrm{N}^{b}$ & 86 & 6 & 2.14 & 1.31 \\
\hline protein chain elongation factor EF-Ts & 16128163 & tsf & b0170 & 25 & 6 & 0.447 & 1.17 \\
\hline 50S ribosomal subunit protein L7/L12 & 16131816 & rplL & b3986 & 7 & 6 & 0.591 & 1.18 \\
\hline cysteine synthase A, $O$-acetylserine sulfhydrolase A & 16130340 & cysK & b2414 & 4 & 3 & 0.504 & 1.69 \\
\hline Glycerophosphodiester phosphodiesterase & 16130174 & $\operatorname{glp} Q$ & b2239 & 31 & 5 & 0.499 & 1.13 \\
\hline 50 S ribosomal subunit protein L32 & 16129052 & rpmF & b1089 & 4 & 1 & 1.962 & 2.73 \\
\hline 50S ribosomal subunit protein L29 & 16131191 & rpmC & b3312 & 21 & 1 & 0.503 & 1.07 \\
\hline Iron superoxide dismutase & 16129614 & $\operatorname{sod} B$ & b1656 & 10 & 2 & 0.601 & 1.10 \\
\hline
\end{tabular}

${ }^{a}$ Ratio of expression level in strains TG1/TOM-Green/EchA-F108L/I219L/C248I vs TG1/TOM-Green/ EchA-wild-type. ${ }^{b}$ No ID number or synonym since protein is from A. radiobacter AD1, not E. coli.
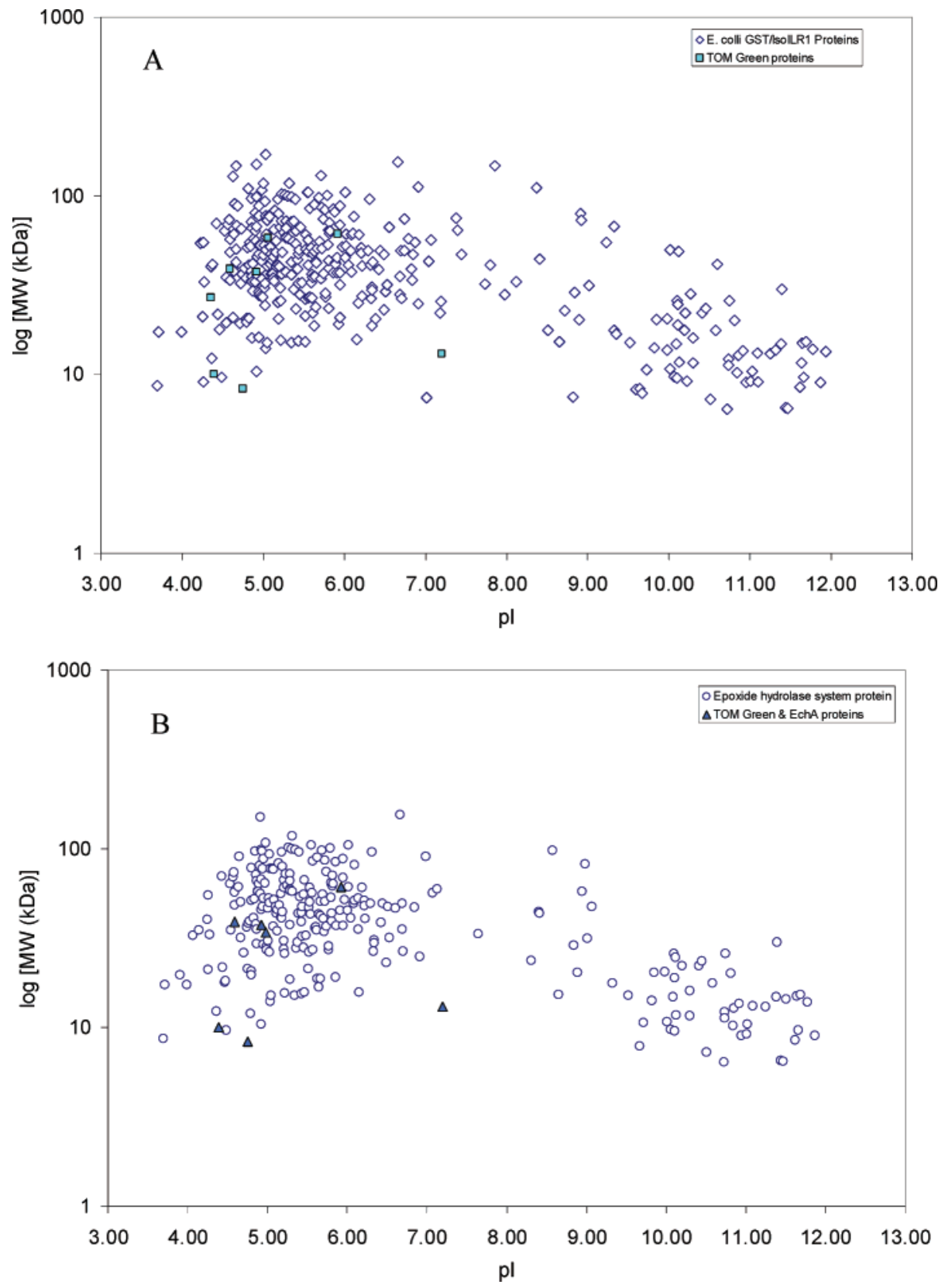

Figure 2. Protein identification and overall proteome coverage across $\mathrm{pl}$ and MW range. (A) E. coli TOM glutathione $S$-transferase system: $\diamond$ denotes wild-type proteins identified in E. coli; $\boldsymbol{\square}$ denotes TOM-Green and GSH/IsolLR1-related proteins identified. (B) $E$. coli epoxide hydrolase system: $\bigcirc$ denotes wild-type proteins identified; $\boldsymbol{\Delta}$ denotes TOM-Green and EchA-related proteins identified. $\mathrm{GSHI}^{*}$; hence, the net result is that more glutathione is proteins involved in the glutathione synthesis pathway was also synthesized. Moreover, the expression level of two other changed significantly in all three strains with TOM-Green 
(Figure 1). Aminomethyltransferase (encoded by $g c v T$ ) and serine hydroxymethyltransferase (encoded by glyA) were repressed 2-6-fold more in the strains with TOM-Green compared to the strain without TOM-Green (Table 2). Although the peptide identification evidence for the down-regulation of aminomethyltransferase has a doubtful statistical basis, similar repression of the well-identified/quantified (4 distinct peptides, 11 replicates; Table 2) serine hydroxymethyltransferase that diverges to a similar intermediate glycine was indicative for validating down-regulation. Aminomethyltransferase initiates the conversion of glycine to $\mathrm{CO}_{2}, \mathrm{NH}_{3}$, and methylene, ${ }^{11}$ and serine hydroxymethyltransferase catalyzes the reversible interconversion of serine and glycine with tetrahydrofolate ${ }^{12}$ (Figure 1). Down-regulation of these proteins may allow greater glycine for glutathione synthesis.

As another interesting enzyme directly related with cis-DCE degradation, tryptophanase (encoded by thaA, primarily degrades L-tryptophan to indole, pyruvate, and ammonia ${ }^{13}$ ) was repressed 5-8-fold in the TOM-Green-containing strains compared to the strain without TOM-Green (Table 2). Since TOMGreen catalyzes indole oxidation ${ }^{14}$ as well as that of cis-DCE, down-regulation of tryptophanase expression may allow more cis-DCE degradation in the TOM-Green systems.

Beyond the proteins involved directly in cis-DCE detoxification, the expression levels of enzymes related to carbon flux, fatty acid synthesis, and oxidative stress proteins were altered due to the introduction of TOM-Green, IsoiLR1, or GSHI* (Table 2). Adding TOM-Green up-regulated the expression levels of ribosomal protein subunits, stress response proteins, a global regulator of starvation conditions, and enzymes involved in pyruvate metabolism. In contrast, enzymes related with the TCA cycle and fatty acid synthesis were down-regulated. Specifically, expression of TOM-Green alone caused a 2-3.6fold up-regulation of the expression of seven ribosomal subunits (out of a total of 47 identified ribosomal $30 \mathrm{~S}$ and $50 \mathrm{~S}$ subunit proteins) including the $30 \mathrm{~S}$ ribosomal subunit proteins S3 (encoded by rpsC); S13 (encoded by rpsM); S16 (encoded by $r p s P$ ); and the $50 \mathrm{~S}$ ribosomal subunit proteins L19 (encoded by rplS), L20 (encoded by rplT), and L32 (encoded by rpmF) compared to the strain without TOM-Green (Table 2). Upon expression of TOM-Green/IsoILR1, the 50S ribosomal subunit protein L32 was increased 3-fold relative to the strain without TOM-Green (Table 2). For the strain containing TOM-Green/ IsoILR/GSHI*, the expression level of the $30 \mathrm{~S}$ ribosomal subunit proteins S3, S13, S16, and the 50S ribosomal subunit proteins L19, L20, L30 (encoded by rpmD), and L33 were induced about 2 -fold compared to the strain without TOM-Green (Table 2). Although the exact roles of all individual ribosomal proteins were not fully characterized, it has been reported that several ribosomal proteins are modulated in response to reactive oxygen species, cadmium, and low temperature. ${ }^{15-17}$ For example, E. coli induces transcription of S3, S10, S19, L2, L4, L6, L10, L23, and L29 upon addition of the superoxidegenerating agent paraquat. ${ }^{16}$ Unlike cis-DCE degradation, the addition of cadmium represses transcription of L2, L3, L4, S3, S5, and S16 but induces transcription of L9 and L20 in E. coli. ${ }^{15}$ Therefore, the results here confirm that the ribosomal proteins S3 (an inducer of antiapoptotic proteins), ${ }^{18}$ S16 (an essential element for $30 \mathrm{~S}$ assembly), ${ }^{19}$ and L20 (involved in negative autogenous regulation $)^{20}$ probably play important roles in the E. coli stress response. Also, these data suggest that the response to cis-DCE degradation in E. coli is similar to the response to reactive oxygen species. Furthermore, the up- regulation of the ribosomal subunit proteins may be a general response to the metabolic engineering, in that the addition of the nine genes here may result in translational limitations. ${ }^{21}$

Overexpression of TOM-Green in the engineered strains led to the production of toxic cis-DCE epoxide and glyoxal; as a result, $d p s$, which encodes the global regulator of starvation conditions and whose protein protects DNA from oxidative or nutritional stresses in E. coli, ${ }^{22}$ was induced 1.5-1.8-fold in the strains with TOM-Green compared to the strain without TOMGreen (Table 2). Up-regulation of this protein probably plays an important role for enhancing the ability of the cells to tolerate intermediates like cis-DCE epoxide and glyoxal.

Moreover, the proteomic data also shows that the expression level of proteins involved in catalysis of hydroperoxides has been changed in all three strains with TOM-Green. The alkyl hydroperoxide reductase subunit [FAD/NAD(P)-binding, encoded by $a h p F]^{23}$ was up-regulated 2-4-fold in all three strains with TOM-Green, and catalase [hydroperoxidase HPI (I), encoded by $k a t G]^{24}$ was up-regulated about 1.8 -fold in the strains with either TOM-Green/IsoILR or TOM-Green/IsoILR/ GSHI* compared to the strain without TOM-Green (Table 2). In contrast, the strains with either TOM-Green or TOM-Green/ IsoILR1 down-regulated the expression level of iron superoxide dismutase (encoded by $\operatorname{sodB}$ ), which catalyzes the conversion of superoxide radicals to hydrogen peroxide and oxygen ${ }^{25}$ (Table 2). These results also support the theory that the stress response mechanism that is incurred during aerobic cis-DCE degradation in E. coli is close to the defense mechanism for reactive oxygen species.

When TOM-Green was introduced, the pyruvate metabolism was also affected (Figure 3). In the strain containing TOMGreen/IsoILR1/GSHI*, the expression level of acetate kinase (encoded by $a c k A$ ) was induced around 3-fold compared to the strain without TOM-Green/IsoILR1/GSHI* (Table 2). Also, the expression level of L-lactate dehydrogenase (encoded by $l l d D$ ) was up-regulated in all three strains with TOM-Green (Figure 3). Lactate dehydrogenase converts lactate to pyruvate in mixed acid fermentations and glucose heterofermentation, ${ }^{26,27}$ and acetate kinase catalyzes the reversible conversion of acetate and acetyl phosphate ${ }^{28}$ (Figure 3). The induction of these enzymes results probably in an increase in the intracellular level of acetyl phosphate or acetyl-CoA (Figure 3), suggesting that the metabolic pathways for energy transfer and carbon source flux were altered in the best-engineered strain for cis-DCE detoxification.

In contrast, the introduction of TOM-Green appears to influence carbon flux by repressing enzymes for the tricarboxylic acid cycle (TCA cycle), gluconeogensis, and fatty acid synthesis (Figure 3). For example, malate dehydrogenase (encoded by $m d h$ ), the enzyme that catalyzes the interconversion of malate and oxaloacetate in the TCA cycle, ${ }^{29}$ was repressed 2-fold in the three strains with TOM-Green compared to the strain without TOM-Green (Table 2, Figure 3). Also, the expression of succinate dehydrogenase (encoded by $s d h B$ ) was repressed about 2 -fold in the strain with TOM-Green/IsoILR1/ GSHI* compared to the strain without TOM-Green (Table 2, Figure 3). Hence, the TCA cycle appears to be affected by the addition of TOM-Green, IsoiLR1, and GSHI*. In addition, enzymes involved in gluconeogensis, for example, phosphoenolpyruvate carboxykinase (encoded by pckA), the enzyme that catalyzes the conversion of oxaloacetate to phosphoenolpyruvate and carbon dioxide, ${ }^{30}$ were repressed 2 -fold in 


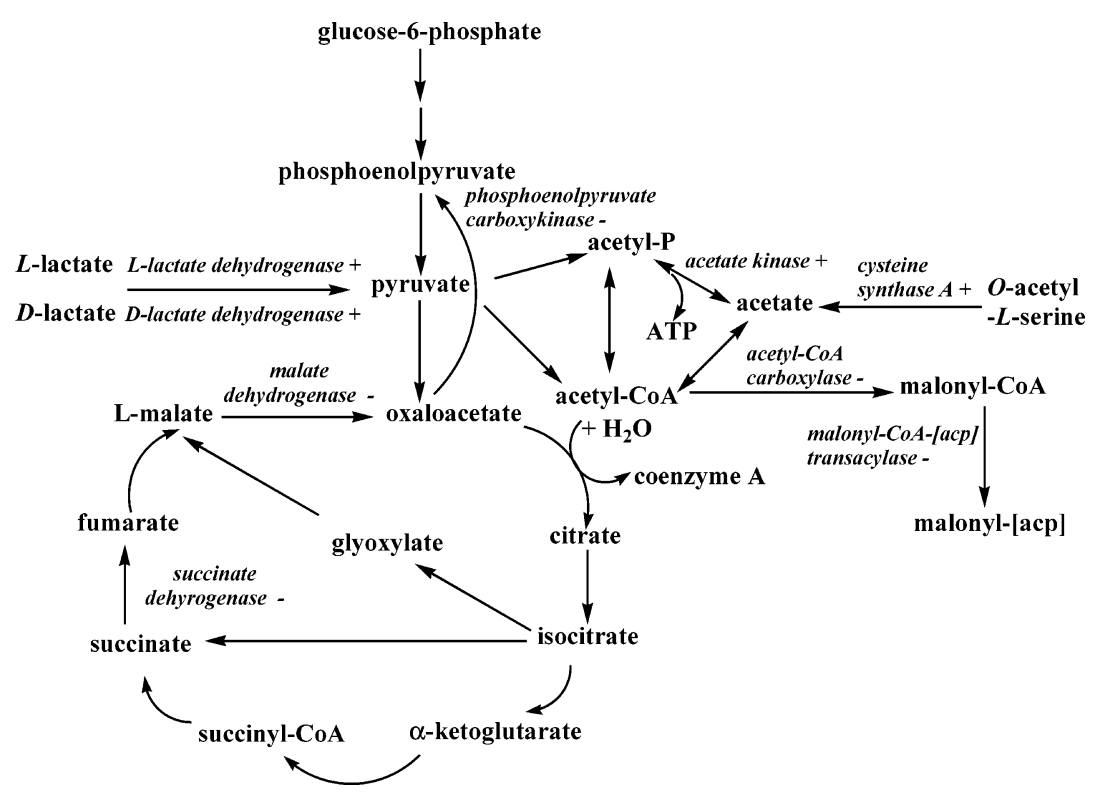

Figure 3. Impact of metabolic engineering on the gluconeogenesis, glyoxylate bypass, and TCA pathways for cis-DCE detoxification by TG1/TOM-Green/IsolLR1/GSHI* and TG1/TOM-Green/EchA-F108L/I219L/C248I. The "+" indicates overexpression, while "-" indicates repression of the proteins. ATP is adenosine triphosphate, Acetyl-P is acetyl phosphate, and [acp] is acyl-carrier-protein.
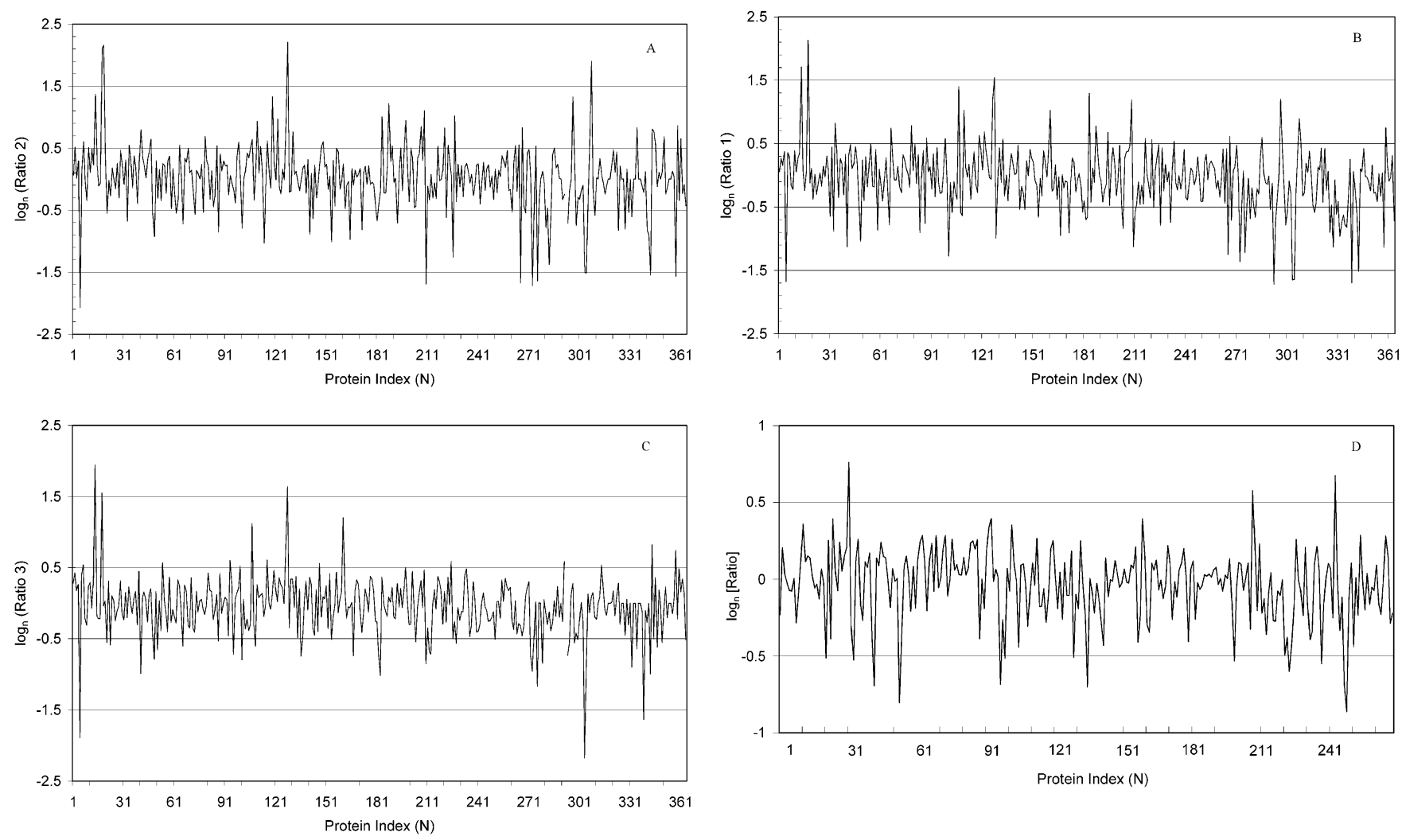

Figure 4. Protein expression ratio comparison across protein index. (A) Protein expression ratio for TG1/pBS(Kan)-TOM-Green/pMMB277IsolLR1-GSHI* against TG1/pBS(Kan)-/pMMB277; (B) protein expressions ratio for TG1/pBS(Kan)-TOM-Green/pMMB277 against TG1/ pBS(Kan)-/pMMB277; (C) protein expressions ratio for TG1/pBS(Kan)-TOM-Green/pMMB277-IsolLR1 against TG1/pBS(Kan)-/pMMB277; (D) epoxide hydrolase system: protein expression ratio for TG1/TOM-Green/EchA-F108L/I219L/C248I against TG1/TOM-Green/EchAwild-type. All plots are presented with a logarithmic scale. Peaks and readings that are nonzero denote differently expressed proteins.

the strains upon adding TOM-Green (Table 2, Figure 3). This probably resulted in reduced concentrations of phosphoenopyruvate and, subsequently, reduced glucose-6-phosphate concentrations in the engineered strains. This suggests carbon flux was re-directed from glucose.
Two enzymes of fatty acid synthesis, malonyl-CoA-[acylcarrier-protein] transacylase (encoded by $f a b D)^{31}$ and acetylCoA carboxylase (biotin carboxylase subunit encoded by $a c c C)^{32}$ were reduced approximately 2 -fold by adding TOM-Green (Table 2), which indicates fatty acid may be significantly altered. 
Acetyl-CoA carboxylase consists of a biotin carboxylase, a carboxyltransferase for carboxylation, and a biotin carboxyl carrier protein for carrying biotin; this enzyme catalyzes the first step in fatty acid synthesis to form malonyl-CoA ${ }^{32}$ (Figure 3). Although the statistical basis for the identification of malonyl-CoA transacylase was not calculated due to the lack of multiple high-scoring peptides (Table 2), the presence of acetyl-CoA carboxylase upstream of the metabolic pathway that also experienced similar down-regulation with better statistical basis provided cross-referencing evidence to the likely reliability of this quantification. The corresponding spectrum was also manually de novo-sequenced and checked for any misinterpretation by the ProQuant software vl.1 (Applied Biosystems, MDS Sciex).

In addition, the expression level of many proteins was changed, although their exact roles in the cis-DCE degradation are unclear (Table 2). All three strains with TOM-Green distinctively up-regulated glycine tRNA synthetase ( $\beta$ subunit, encoded by glyS), chaperone Hsp90 (heat shock protein C 62.5, encoded by $h t p G$ ), the periplasmic molecular chaperone for outer membrane proteins (encoded by $h \operatorname{lpA}$ ), and uridine phosphorylase (encoded by $u d p$ ), while these strains significantly down-regulated glycerophosphodiester phosphodiesterase (periplasmic, encoded by $g l p Q$ ) and membrane-bound ATP synthase (F1 sector, $\delta$-subunit, encoded by atpH).

Epoxide Hydrolase System Proteome. Out of the 268 proteins identified from both E. coli TG1 strains harboring TOM-Green/EchA-wild-type and TOM-Green/EchA F108L/ I219L/C248I (Figure 2), the expression level of 8 proteins changed significantly (Table 3 ) due to the metabolic engineering which produced the first active epoxide hydrolase for chlorinated ethenes. ${ }^{3}$ Since we compared the evolved EchA versus the wild-type EchA enzyme, less proteins changed in the epoxide hydrolase system compared to adding extra enzymes in the glutathione $S$-transferase system. Both EchA and the 50S ribosomal subunit protein L32 in the strain with the evolved EchA F108L/I219L/C248I were expressed about 2 -fold greater that the strain which contained wild-type EchA (Table 3). Intriguingly, the expression of L32 was up-regulated in the strain with TOM-Green/EchA F108L/I219L/C248I as well as in all three TOM-Green systems. $r p m F$ encoding ribosomal protein L32 is upstream of $p l s X$ (unknown function) and the $f a b$ cluster (encoding key fatty acid synthetic enzymes). ${ }^{33}$ Cotranscription of rpmF and plsX plays an important role in the coordinate regulation of ribosomes and cell membrane synthesis, ${ }^{33,34}$ so perhaps L32 was expressed along with these other loci. However, other proteins such as protein chain elongation factor EF-Ts, the 50S ribosomal subunit proteins L7/L12/L29, and iron superoxide dismutase in the EchA triple mutant system were decreased about 2-fold compared to the strain with wild-type EchA (Table 3). It is interesting that the protein level of superoxide dismutase was down-regulated in the EchA triple mutant as well as in the TOM-Green system compared to their respective controls. The expression level of cysteine synthase A and glycerophosphodiester phosphodiesterase in the strain with EchA-F108L/I219L/C248I were also decreased 2-fold compared to the strain with wild-type EchA. We note that no extra cysteine is needed for the reaction carried out by EchA toward cis-DCE epoxide (water takes the place of glutathione) (Figure 1); hence, in the strain with EchA F108L/ I219L/C248I, the metabolic pathway of the GST/GSHI* system was repressed 2-fold with a lower expression level of cysteine synthase A compared with the strain containing the wild-type
EchA. These results also suggest lower expression of these enzymes in the strain containing EchA F108L/I219L/C248I was useful for greater cis-DCE degradation.

\section{Discussion}

We show clearly in this work that the physiology of E. coli cells is altered when contacted with $1 \mathrm{mM}$ cis-DCE by the introduction of TOM-Green, IsoILR1, and GSHI* or by engineering EchA from wild-type to the F108L/I219L/C248I variant so that the epoxide hydrolase effectively detoxifies the chlorinated epoxide formed from TOM-Green oxidation of cis-DCE. We used a multiplexed peptide quantification technique (iTRAQ) ${ }^{6}$ to identify and quantify the protein expression changes between control cells and engineered $E$. coli cells. The proteomic data clearly show the beneficial changes of the expression level of important enzymes involved in the metabolic pathway of cis-DCE degradation (Figure 1). The data also show that the TCA cycle, the fatty acid formation pathway, and acetyl-CoA pathway were probably influenced by the introduction of TOMGreen, IsoILR1, and GSHI* (Figure 3). Moreover, this study elucidates a number of interesting stress-activated proteins that were regulated during aerobic degradation of cis-DCE.

As expected, the expression levels of enzymes involved directly in cis-DCE detoxification pathway were up-regulated in the glutathione $S$-transferase system by the introduction of TOM-Green, IsoILR1, and GSHI* (Figure 1). Hence, to enhance cis-DCE detoxification, the cell overexpresses cysteine synthase A and represses aminomethyltransferase and serine hydroxymethyltransferase to achieve higher concentrations of intracellular glutathione. Although glutathione synthetase (encoded by gshB) (Figure 1) was not identified in this study, overexpression of glutathione synthetase which produces glutathione or addition of exogenous glutathione may further enhance cis-DCE detoxification in the E. coli strain with TOM-Green/IsoILR1/ GSHI*. Use of a tryptophanase (tnaA) knockout strain that forms less indole may also help cis-DCE oxidation because indole serves as a competitive substrate for TOM-Green.

The engineered strains in both systems produce toxic intermediates, such as cis-DCE epoxide and glyoxal (Figure 1). Although cis-DCE epoxide degradation has been addressed with our engineered cells, the toxicity of glyoxal remains. This may be addressed by identifying or evolving an enzyme that can convert glyoxal into a product capable of being utilized in central metabolism cycles. ${ }^{4}$ For example, overexpression of glyoxalase I and glyoxalase II that catalyze the conversion of methylglyoxal into D-lactate ${ }^{35}$ or overexpression of aldehyde dehydrogenase that could theoretically catalyze glyoxal into glyoxylate (Figure 3) may be beneficial for channeling glyoxal into a central metabolic cycle. ${ }^{36}$

Other metabolic pathways such as the TCA cycle, gluconeogensis, the acetyl-CoA pathway, and fatty acid synthesis were affected by the metabolic engineering (Figure 3). As the key compound related to gluconeogenesis and the TCA cycle, L-malate plays an important role in carbon flux in E. coli (Figure $3) .{ }^{26,37}$ In the TCA cycle, succinate is converted to fumarate by succinate dehyrogenase and is sequentially catalyzed to malate by fumarase. ${ }^{26}$ Repression of succinate dehydrogenase (an Fe-S protein) in the TCA cycle should lead to less L-malate generated from fumarate (Figure 3).

Acetyl-CoA is a precursor of many different molecules including citrate, lipids, and fermentation end products ${ }^{26}$ (Figure 3). The accumulation of acetyl-CoA in the strain containing TOM-Green/IsoILR1/GSHI* was probably from (i) 
2-fold depression of fatty acid synthesis; (ii) 2-fold induction of cysteine synthase A which produces acetate and cysteine formed from $O$-acetyl-L-serine; 38 (iii) 3.8 -fold induction of acetate kinase, which converts acetyl phosphorate to acetate in the mixed acid fermentation; ${ }^{26}$ and iv) 1.7-fold up-regulation of a lactate dehydrogenase (Figure 3). Since some of the components of the TCA cycle and fatty acid synthesis pathways were down-regulated in the engineered cells compared to the control cells, the strains with TOM-Green might try to use acetyl-CoA to produce ATP via acetyl phosphate during cisDCE degradation (Figure 3). This speculation may partially explain the higher cell viability with the strain that contains TOM-Green/IsoILR1/GSHI* (Table 2).

Over 20 years, a variety of approaches using two-dimensional electrophoresis and DNA microarrays has led to the identification of various important reactive oxygen-activated genes including katG, ahpF, dps, gorA, oxyS, grxA, fur, trxC, dsbG, $f h u F$, and $f l u .{ }^{39}$ In this study, a quantitative shotgun approach identified that the expression levels of three proteins, catalase (encoded by $k a t G$ ), alkyl hydroperoxide reductase subunit (encoded by $a h p F$ ), and a global regulator (encoded by $d p s$ ), were up-regulated (1.5-4.0-fold) in all three E. coli strains with TOM-Green compared to the strain without TOM-Green (Table 2). Also, we could detect that the expression level of iron superoxide dismutase (encoded by $\operatorname{sod} B)^{25}$ was influenced; this protein is another interesting reactive oxygen-activated protein. ${ }^{25}$ Moreover, a total of nine interesting ribosomal proteins including S3, S16, L20, and L32 were significantly up-regulated (Table 2) during aerobic cis-DCE degradation which may indicate they, like other ribosomal proteins, are playing a significant role in oxygen-related stress response as a result of converting cis-DCE to $c i s$-DCE epoxide and glyoxal or that there is a translational limitation. ${ }^{21}$

In this study, the proteomic data provide important insights into the metabolic and physiological changes that occur upon cis-DCE degradation by engineered E. coli strains. Since the number of identified proteins in this quantitative proteomic approach is less than the number of genes, a DNA microarray analysis may complement this proteomic approach.

Acknowledgment. This research was supported by the National Science Foundation (BES-0331416) and the United Kingdom's Engineering and Physical Sciences Research Council (EPSRC) (GR/S84347/01). P.C.W. also thanks the EPSRC for provision of an Advanced Research Fellowship (GR/A11311/ 01).

Supporting Information Available: Expression ratios, $P$-values, and error factors for proteins identified from the glutathione $S$-transferase and the epoxide hydrolase systems; false-positive identification lists; and ion chromatograms. This material is available free of charge via the Internet at http:// pubs.acs.org.

\section{References}

(1) Ryoo, D.; Shim, H.; Canada, K.; Barbieri, P.; Wood, T. K. Nat. Biotechnol. 2000, 18, 775-778.

(2) McCarty, P. L. Science 1997, 276, 1521-1522.

(3) Rui, L.; Cao, L.; Chen, W.; Reardon, K. F.; Wood, T. K. J. Biol. Chem. 2004, 279, 46810-46817.
(4) Rui, L.; Kwon, Y. M.; Reardon, K. F.; Wood, T. K. Environ. Microbiol. 2004, 6, 491-500.

(5) Canada, K. A.; Iwashita, S.; Shim, H.; Wood, T. K. J. Bacteriol. 2002, 184, 344-349.

(6) Ross, P. L.; Huang, Y. N.; Marchese, J. N.; Williamson, B.; Parker, K.; Hattan, S.; Khainovski, N.; Pillai, S.; Dey, S.; Daniels, S.; Purkayastha, S.; Juhasz, P.; Martin, S.; Bartlet-Jones, M.; He, F.; Jacobson, A.; Pappin, D. J. Mol. Cell. Proteomics 2004, 3, 11541169.

(7) Aggarwal, K.; Choe, L. H.; Lee, K. H. Proteomics 2005, 5, $2297-$ 2308.

(8) Sambrook, J.; Fritsch, E. F.; Maniatis, T. Molecular Cloning: A Laboratory Manual, 2nd ed.; Cold Spring Harbor Laboratory Press: Cold Spring Harbor, New York, 1989.

(9) Chong, P. K.; Gan, C. S.; Pham, T. K.; Wright, P. C. J. Proteome Res. 2006, published online Mar 25, http://dx.doi.org/10.1021/ pr060018u.

(10) Rabeh, W. M.; Cook, P. F. J. Biol. Chem. 2004, 279, 26803-26806.

(11) Wonderling, L. D.; Urbanowski, M. L.; Stauffer, G. V. Microbiology 2000, 146, 2909-2918.

(12) Schirch, V.; Szebenyi, D. M. Curr. Opin. Chem. Biol. 2005, 9, 482487.

(13) Gong, F.; Yanofsky, C. J. Biol. Chem. 2002, 277, 17095-17100.

(14) Rui, L.; Reardon, K. F.; Wood, T. K. Appl. Microbiol. Biotechnol. 2005, 66, 422-429.

(15) Wang, A.; Crowley, D. E. J. Bacteriol. 2005, 187, 3259-3266.

(16) Pomposiello, P. J.; Bennik, M. H.; Demple, B. J. Bacteriol. 2001, 183, 3890-3902.

(17) Sahara, T.; Goda, T.; Ohgiya, S. J. Biol. Chem. 2002, 277, 5001550021.

(18) Ruggero, D.; Pandolfi, P. P. Nat. Rev. Cancer 2003, 3, 179-192.

(19) Persson, B. C.; Bylund, G. O.; Berg, D. E.; Wikstrom, P. M. J. Bacteriol. 1995, 177, 5554-5560.

(20) Olsson, C. L.; Graffe, M.; Springer, M.; Hershey, J. W. Mol. Gen. Genet. 1996, 250, 705-714.

(21) Wood, T. K.; Peretti, S. W. Biotechnol. Bioeng. 1990, 36, 865878.

(22) Zhao, G.; Ceci, P.; Ilari, A.; Giangiacomo, L.; Laue, T. M.; Chiancone, E.; Chasteen, N. D. J. Biol. Chem. 2002, 277, 2768927696.

(23) Bieger, B.; Essen, L. O. J. Mol. Biol. 2001, 307, 1-8.

(24) Hillar, A.; Peters, B.; Pauls, R.; Loboda, A.; Zhang, H.; Mauk, A. G.; Loewen, P. C. Biochemistry 2000, 39, 5868-5875.

(25) Kim, S. Y.; Nishioka, M.; Hayashi, S.; Honda, H.; Kobayashi, T.; Taya, M. Appl. Environ. Microbiol. 2005, 71, 2762-2765.

(26) White, D. The Physiology and Biochemistry of Prokaryotes; Oxford University Press: New York, 2000.

(27) Lu, Z.; Cabiscol, E.; Obradors, N.; Tamarit, J.; Ros, J.; Aguilar, J.; Lin, E. C. C. J. Biol. Chem. 1998, 273, 8308-8316.

(28) Fox, D. K.; Roseman, S. J. Biol. Chem. 1986, 261, 13487-13497.

(29) Park, S.-J.; Cotter, P. A.; Gunsalus, R. P. J. Bacteriol. 1995, 177, $6652-6656$.

(30) Delbaere, L. T. J.; Sudom, A. M.; Prasad, L.; Leduc, Y.; Goldie, H. Biochim. Biophys. Acta 2004, 1697, 271-278.

(31) Serre, L.; Verbree, E. C.; Dauter, Z.; Stuitje, A. R.; Derewenda, Z. S. J. Biol. Chem. 1995, 270, 12961-12964.

(32) Li, S.-J.; Cronan, J. E., Jr. J. Biol. Chem. 1992, 267, 855-863.

(33) Podkovyrov, S.; Larson, T. J. FEBS Lett. 1995, 368, 429-431.

(34) Zhang, Y.; Cronan, J. E., Jr. J. Bacteriol. 1998, 180, 3295-3303.

(35) Clugston, S. L.; Barnard, J. F.; Kinach, R.; Miedema, D.; Ruman, R.; Daub, E.; Honek, J. F. Biochemistry 1998, 37, 8754-8763.

(36) van Hylckama Vlieg, J. E. T.; Janssen, D. B. J. Biotechnol. 2001, 85, 81-102.

(37) Cronan, J. E., Jr.; LaPorte, D. In Escherichia coli and Salmonella: Cellular and Molecular Biology, 2nd ed.; Neidhardt, F. C., Ed.; ASM Press: Washington, DC, 1996; pp 206-216.

(38) Kredich, N. M. In Escherichia coli and Salmonella: Cellular and Molecular Biology, 2nd ed.; Neidhardt, F. C., Ed.; ASM Press: Washington, DC, 1996; pp 514-527.

(39) Zheng, M.; Wang, X.; Templeton, L. J.; Smulski, D. R.; LaRossa, R. A.; Storz, G. J. Bacteriol. 2001, 183, 4562-4570.

PR060008T 